\title{
Hereditary geniospasm
}

INSERM

\section{Source}

INSERM. (1999). Orphanet: an online rare disease and orphan drug data base. Hereditary geniospasm. ORPHA:53372

Hereditary geniospasm is a movement disorder characterized by episodes of involuntary tremor of the chin and lower lip. 